\title{
Comparison of the activity of short stay independent hospitals in England and Wales, 1981 and 1986
}

\author{
J P Nicholl, N R Beeby, B T Williams
}

\begin{abstract}
From a sample of 19000 treatment episodes at 183 of the 193 independent hospitals with operating facilities in England and Wales that were open during 1986 it is estimated that $\mathbf{4 0 4 0 0 0}$ inpatients were treated in 1986 (an increase of $48 \%$ since 1981) and 99000 day cases (an increase of $112 \%$ ). It was found that the procedure most commonly performed was abortion, though this made up only $19 \%$ of the total caseload in 1986 compared with $30 \%$ in 1981 , otherwise the case mix in 1986 was similar to that in 1981. Fewer patients came from overseas in 1986 than in 1981, but the distribution by age and sex remained the same, with three quarters of the patients aged between 15 and 65 . The estimated bed occupancy in the independent hospitals in 1986 was less than $60 \%$ nationally and only $52 \%$ in the Thames regions.

It is concluded that in these five years the nature of the independent hospital sector changed little, and in 1986 the activity still consisted largely of routine cold elective surgery for people of working age, and the regional differences in admission rates to independent hospitals were nearly as great as in $\mathbf{1 9 8 1}$.
\end{abstract}

\section{Introduction}

In 1981 there were 153 independent hospitals with operating theatre facilities in England and Wales with 6592 private beds not contracted to the National Health Service. The hospitals ranged in size from seven to 263 beds (mean 43). ${ }^{1}$ By December 1986 it was reported that there were 9526 beds available in 187 hospitals. ${ }^{2}$ Whereas in 1981 the majority $(59 \%)$ of these independent hospital beds were owned by charitable organisations, by 1986 this share had fallen to $47 \%$, with for profit organisations owning the majority.

A comprehensive picture of activity in independent hospitals in 1981 is available,' which together with known changes in the ownership structure of the independent hospital sector has encouraged the belief that the independent hospital sector could now make a substantial contribution to easing the current difficulties facing the NHS. But some commentators have noted, for example, the considerable regional imbalance in the provision of independent hospital facilities, the demographic characteristics of the insured population, and many other claimed shortcomings and have doubted the capacity of the private sector to make much of a contribution. ${ }^{3+}$

Besides short stay independent hospitals with operating facilities the private sector has two further major components: longer stay private nursing homes and pay beds in NHS hospitals. This paper is concerned only with short stay independent hospital activity. A companion paper ( $p$ 243) adds in the pay bed component to examine the role of the private sector in short term care in England and Wales. ${ }^{5}$ We have not investigated activity in the private nursing home sector.

To investigate what changes have actually occurred in the independent hospital sector since 1981 we carried out a study of the volume and nature of the clinical caseload and clientele of the independent hospitals based on records of patients admitted during sampled time periods in 1986 . This is a report of the main findings.

\section{Methods}

All the independent acute hospitals in England and Wales that were open at any time in 1986 were identified from lists of independent hospitals with operating theatres kept by the Independent Hospitals Association ${ }^{2}$ and the Department of Health and Social Security ${ }^{6}$ and from lists published in the Directory of Independent Hospitals and Health Services.

A sample period during 1986 was allocated to each hospital in the study, and for each patient admitted as an inpatient or day patient during the period administrative, demographic, and clinical details were recorded. All operations or procedures carried out were coded using the Office of Population Censuses and Surveys classification, ${ }^{8}$ although only the main operation is tabulated here. As in our study of activity in independent hospitals in $1981^{\prime}$ patients admitted to NHS contractual beds were excluded, but data on outpatients, which had been found to be comparatively unreliable in 1981, were not collected. Accordingly, the estimates for 1981 presented here have been recalculated to exclude outpatients. To enhance comparability between results the hospitals that had provided data for the 1981 study were sampled for the same periods in 1986. Hospitals that had opened since 1981 were allocated sample periods of a duration so that, based on the number of beds in the hospital, it was expected that roughly 100 admissions would be sampled from each hospital and at a time of year so that within a region a similar amount of data would be collected for each season.

The data were coded and stored on computer file. In estimating the whole year activity sample numbers were weighted to take account of the length of the sample period and the time of year, and a small correction factor was applied to allow for the absence of data from 10 hospitals. The weighting and rounding of estimates mean that the totals in the tables do not always equal the sum of the elements.

\section{Results}

There were 193 short stay independent hospitals with operating theatre facilities which admitted some private patients at some time in 1986 in England and Wales. These hospitals had a total of 9466 beds and ranged in size from two to 265 beds (mean 49). There were seven other hospitals with a total of 123 beds which were excluded because they worked entirely on contract to the NHS (one), had no admsisions in 1986 (four), or were exclusively hair clinics (two).

Ten of the 193 eligible hospitals refused to cooperate and were not included in the study, five rejecting our approaches or those made on our behalf and five failing to respond at all. This represents a loss to the study of 328 beds, which is $3.5 \%$ of the total number available. Eight of the 10 hospitals which did not cooperate were "for profit" hospitals and two were charitable hospitals. 
LEVEL OF ACTIVITY

From samples of 12959 patient records in 1981 and 18908 in 1986 it was estimated that the number of cases treated as inpatients or day cases rose from 320630 to 503260 , an increase of $57 \%$. The estimated numbers treated in the 31 Nuffield hospitals in 1986 was within $0.1 \%$ of the number actually treated according to the records of that organisation (Nuffield Nursing Homes Trust, private communication). The estimated number of abortions was $4 \%$ less than the actual number reported in non-NHS hospitals in England and Wales in $1986 .{ }^{4}$ Most of the shortfall is probably due to the fact that two of the hospitals that did not cooperate specialised in abortions (private communi(ation)."

Of the estimated 503260 cases admitted, 401920 $(79.9 \%)$ were inpatients and $98390(19.6 \%)$ were day cases. The state of the remaining $2950(0.6 \%)$ was unknown. The respective figures in 1981 were 270970 $(84 \cdot 5 \%), 46340(14 \cdot 4 \%)$, and $3290(1 \cdot 1 \%)$. Over the period the number of day cases treated had increased by $112 \%$ and the number of inpatients by $48 \%$.

\section{CLINICAL CASELOAD}

In 1986 by far the largest component of the estimated total caseload of the independent hospitals was abortion, just as it was in 1981, although proportionately it had decreased from $30 \%$ of the total activity in 1981 to $19 \%$ in 1986 (including overseas residents). Excluding alortions, there were an estimated 337110 inpatient admissions in 1986 and 74740 day cases, representing increases of $72 \%$ and $164 \%$ respectively over the comparable 1981 figures (195630 and 28370).

Apart from abortions the clinical activity remained varied but was predominantly elective surgery. As in 1981 most of the operations on residents of England and Wales were those for which waiting lists occur in the NHS (table I). The distributions of types of operation carried out in 1981 and 1986 were similar. The numbers of nearly every operation or procedure increased, however, and some appreciably so such as arthroplasty and other orthopaedic operations and major abdominal surgery, including cholecystectomy. The greatest increase was in coronary artery bypass grafts and other heart operations which went from an estimated 640 in 1981 to 3830 in 1986, an increase of nearly $600 \%$. Fewer than a thousand coronary artery bypass grafts were carried out on residents of England and Wales in 1986, however. The only clinically important category which showed a decrease was sterilisation by procedures on the oviducts. The increasing impact of day surgery and procedures was clear in relation to other heart operationsmainly investigations by cardiac catheterisation - and endoscopic examinations.

The swing towards for profit facilities in the independent sector has not affected the overall case mix to any appreciable extent, largely because the case mix in the charitable and for profit sectors is similar (table $\mathbf{I}$ ). Only heart surgery was obviously more noticeable in the for profit sector than in the charitable sector, although absolute numbers were small. On the other hand, arthroplasties were more common in charitable hospitals.

\section{PATIENTS}

The proportion of patients who were residents of the United Kingdom rose from $84 \%$ in 1981 to $91 \%$ in 1986. As in 1981 all but $1 \%$ of these were from England and Wales. Abortion was the reason for admission for only one out of every seven residents of England and Wales - one in four in 1981 - but it was still the reason for admission of three quarters of the patients from other parts of the United Kingdom and Europe (table II).

Excluding terminations of pregnancy, the distribution by age and sex of patients in independent hospitals in 1986 was similar to that in 1981 (table III). Females outnumbered males, and three quarters of those treated were of working age.

\section{REGIONAL DIFFERENCES}

The ratio of independent hospital beds to population varied by a factor of 12 between the lowest English

TABLE I-Estimated numbers of operations carried out in independent hospitals, charitable and for profit, on residents of England and Wales

\begin{tabular}{|c|c|c|c|c|c|c|}
\hline \multirow{3}{*}{$\begin{array}{l}\text { Main operation or procedure } \\
\text { (Office of Population Censuses } \\
\text { and Survey's operation codes }\end{array}$} & \multirow{2}{*}{\multicolumn{2}{|c|}{ Estimated numbers $\dagger$}} & \multicolumn{4}{|c|}{ Case mix } \\
\hline & & & \multicolumn{2}{|c|}{ All hospitals $(\%)$} & \multirow{2}{*}{$\begin{array}{c}\text { Charitable } \\
\text { hospitals }(\%) \\
1986\end{array}$} & \multirow{2}{*}{$\begin{array}{c}\text { For profit } \\
\text { hospitals (\%) } \\
1986\end{array}$} \\
\hline & 1981 & 1986 & 1981 & 1986 & & \\
\hline Lens operations $(170-179)$ & 3935 & 8491 & 1.9 & $2 \cdot 2$ & $2 \cdot 4$ & $2 \cdot 1$ \\
\hline Other eve operations $(100-169,189-189)$ & 3086 & 6125 & 1.5 & 1.6 & 1.7 & 1.6 \\
\hline Tonsillectomy and adenoidectomy $(230-239)$ & 9229 & 12115 & $4 \cdot 5$ & $3 \cdot 2$ & $3 \cdot 4$ & $3 \cdot 0$ \\
\hline Other ear, nose, and throat & 12811 & 24789 & $6 \cdot 2$ & 6.5 & $7 \cdot 1$ & $6 \cdot 0$ \\
\hline Dental extraction $(251,252)$ & 7344 & 14504 & $3 \cdot 5$ & $3 \cdot 8$ & $3 \cdot 4$ & $4 \cdot 1$ \\
\hline Coronary artery bypass graft (304) & 374 & 929 & $0 \cdot 2$ & $0 \cdot 2$ & $<0 \cdot 1$ & $0 \cdot 4$ \\
\hline All other heart operations & 234 & 2902 & $0 \cdot 1$ & 0.8 & 0.1 & $1 \cdot 3$ \\
\hline Abdominal hernia repair $(410-419)$ & 9435 & 15664 & $4 \cdot 6$ & $4 \cdot 1$ & $4 \cdot 8$ & $3 \cdot 6$ \\
\hline Major intra-abdominal & 6117 & 10198 & $3 \cdot 0$ & $2 \cdot 7$ & $2 \cdot 6$ & $2 \cdot 7$ \\
\hline Haemorrhoidectomy and other anal/perianal & 5483 & 6562 & $2 \cdot 6$ & $1 \cdot 7$ & 1.9 & $1 \cdot 6$ \\
\hline Appendicectomy $(440-444)$ & 1694 & 2350 & $0 \cdot 8$ & $0 \cdot 6$ & 0.5 & $0 \cdot 7$ \\
\hline Prostatectomy $(630-635)$ & 2803 & 4585 & $1 \cdot 4$ & $1 \cdot 2$ & $1 \cdot 4$ & $1 \cdot 0$ \\
\hline Vasectomy 651 ) & 2546 & 4912 & $1 \cdot 2$ & $1 \cdot 3$ & 1.6 & $1 \cdot 0$ \\
\hline Circumcision 661$)$ & 2490 & 3605 & $1 \cdot 2$ & $0 \cdot 9$ & 1.0 & 1.9 \\
\hline Dilatation and curettage, etc (703-706) & 11973 & 20915 & $5 \cdot 8$ & $5 \cdot 5$ & $5 \cdot 2$ & 5.8 \\
\hline All hysterectomy $(690)-696$ & 9211 & 13843 & $4 \cdot 5$ & $3 \cdot 6$ & 3.9 & $3 \cdot 4$ \\
\hline Division/ligation/occlusion oviducts & 4035 & 2819 & 1.9 & 0.7 & $1 \cdot 0$ & 0.5 \\
\hline ()ther gynaecological & 6629 & 11071 & $3 \cdot 2$ & $2 \cdot 9$ & $2 \cdot 2$ & $3 \cdot 5$ \\
\hline Athroplasty $(810-814)$ & 6328 & 10080 & $3 \cdot 1$ & $2 \cdot 6$ & 3.5 & 1.9 \\
\hline Other orthopaedic & 16537 & 35353 & $8 \cdot 0$ & $9 \cdot 3$ & $9 \cdot 3$ & $9 \cdot 3$ \\
\hline Ligation/stripping varicose veins $(893,894)$ & 7429 & 10505 & 3.6 & $2 \cdot 8$ & 3.6 & $2 \cdot 1$ \\
\hline $\begin{array}{l}\text { Plastic operations } \\
\text { Plons }\end{array}$ & 3825 & 4539 & 1.8 & $1 \cdot 2$ & $1 \cdot 0$ & $1 \cdot 4$ \\
\hline ()ther skin, subcutaneous $910-919)$ & 8972 & 24478 & $4 \cdot 3$ & $6 \cdot 4$ & $5 \cdot 4$ & $7 \cdot 2$ \\
\hline All endoscopic examinations & 11012 & 31535 & $5 \cdot 3$ & $8 \cdot 3$ & $8 \cdot 0$ & $8 \cdot \overline{5}$ \\
\hline All other operations and procedures & 36496 & 64446 & $17 \cdot 6$ & $16 \cdot 9$ & 15.9 & $17 \cdot 7$ \\
\hline No operation or procedure & 16930 & 34290 & $8 \cdot 2$ & $9 \cdot 0$ & $9 \cdot 1$ & 8.9 \\
\hline All known non-abortion operations (total) & 206920 & 381605 & $100 \%$ & $100 \%$ & 174074 & 207531 \\
\hline Abortions $(742,750,769)$ & 66027 & 68956 & $23 \cdot 9 \%$ & $14 \cdot 9 \%$ & $20 \cdot 7 \%$ & $9 \cdot 4 \%$ \\
\hline Not known & 2805 & 11106 & $1 \cdot 0 \%$ & $2 \cdot 4 \%$ & $1 \cdot 8 \%$ & $3 \cdot 0 \%$ \\
\hline All & 275752 & 461666 & & & 224640 & 237026 \\
\hline
\end{tabular}

* Where the operation code list is not given, a list of the operations which were included is available from the authors on request.

tThese estimates include a proportion of the patients whose country of residence was not known. 
TABLE II-Estimated numbers admitted to independent hospitals in 1981 and in 1986 by country of residence, and proportion of admissions that were for abortions

\begin{tabular}{lrrrrrr}
\hline & \multicolumn{2}{c}{$\begin{array}{c}\text { No of inpatients and } \\
\text { day cases }\end{array}$} & & & \multicolumn{2}{c}{$\begin{array}{c}\text { Proportion }(\%) \text { having } \\
\text { an abortion }\end{array}$} \\
\cline { 2 - 3 } \cline { 6 - 7 } Country of residence & 1981 & 1986 & & 1981 & 1986 \\
\hline England and Wales & 267490 & 457370 & & $24 \cdot 2$ & $15 \cdot 3$ \\
Other countries in the United Kingdom & 3110 & 3190 & & $79 \cdot 1$ & $78 \cdot 4$ \\
Republic of Ireland and Europe & 30340 & 26020 & & $85 \cdot 5$ & $74 \cdot 4$ \\
Outside Europe & 12800 & 11060 & & $9 \cdot 8$ & $7 \cdot 9$ \\
Not known & 9690 & 5630 & & $43 \cdot 4$ & $8 \cdot 8$ \\
\hline All countries & 323440 & 503260 & & $30 \cdot 3$ & $18 \cdot 6$ \\
\hline
\end{tabular}

TABLE III-Age distribution (percentages) of residents of England and Wales treated in independent hospitals in 1981 and 1986 (excludes maternity cases and termination of pregnancy)

\begin{tabular}{lcccccccc}
\hline & \multicolumn{9}{c}{1981} & & \multicolumn{3}{c}{1986} \\
\cline { 2 - 3 } Age (years $)$ & $\begin{array}{c}\text { Male } \\
(\mathrm{n}=83909)\end{array}$ & $\begin{array}{c}\text { Female } \\
(\mathrm{n}=117224)\end{array}$ & $\begin{array}{c}\text { Persons } \\
(\mathrm{n}=201\end{array}$ & & $\begin{array}{c}\text { Male } \\
(\mathrm{n}=163)^{\star}\end{array}$ & $\begin{array}{c}\text { Female } \\
(\mathrm{n}=219991)\end{array}$ & $\begin{array}{c}\text { Persons } \\
(\mathrm{n}=384741)^{\star}\end{array}$ \\
\hline $0-14$ & 12 & 6 & 8 & & 11 & 6 & 8 \\
$15-44$ & 36 & 47 & 43 & & 36 & 47 & 42 \\
$45-64$ & 34 & 31 & 33 & & 35 & 31 & 33 \\
$\geqslant 65$ & 18 & 16 & 17 & & 19 & 16 & 17 \\
\hline
\end{tabular}

* Sex or age not known in 7362 cases in 1981 and 6235 cases in 1986.

region and the highest - not as great a difference as in 1981 , when the ratio varied by a factor of 25 - but the rankings of the various regions remained much the same (table IV). The number of independent hospital beds per 100000 population remained lowest in the Northern region and highest in the Thames regions. The number of beds increased in every region, however. (There was a transfer of a health district in 1982 from North West Thames to North East Thames, so the figures for these regions should be aggregated.)
The increase in bed supply in the Thames regions, which were already well provided for in 1981 (an addition of 8.6 beds per 100000 population), was greater than in any other region except Wessex.

Overall, the increase of $66 \%$ in the admission rates to independent hospitals between 1981 and 1986 reflected the percentage increase $(42 \%)$ in availability of beds and this pattern was observed in the various regions. Consequently, the range of the admission rates in 1986 (285 to 1574) was nearly as great as in 1981 (142 to 1007). On each occasion the widest difference was between the Northern and South West Thames regions.

\section{BED OCCUPANCY}

On the assumption that a day case patient occupies a bed for one day and an inpatient for the number of nights spent in hospital the estimated average daily occupancy, calculated as the ratio of the estimated number of bed days used to bed days available, for all the acute sector independent hospital beds in 1986 was $57 \%$. This is substantially less than the average daily occupancy of $74 \%$ in NHS and amenity beds in acute specialties in $1986 .{ }^{10}$ In fact, since the NHS statistics do not count as occupied any bed that is temporarily used by a day case during the day which is not otherwise in use by an inpatient, the directly comparable NHS figure would be yet higher.

Excluding 14 hospitals whose activity was almost exclusively abortions, the average daily occupancy in the independent hospitals was $55 \%$, but there were considerable differences between types of hospital. The estimated occupancy of Nuffield hospitals was $66 \%$ compared with only $39 \%$ in hospitals managed by religious foundations. The occupancy rates of for profit

TABLE IV - Regional bed distribution and use in independent short stay hospitals

\begin{tabular}{|c|c|c|c|c|c|c|c|}
\hline \multirow[b]{3}{*}{ Region } & \multirow{2}{*}{\multicolumn{2}{|c|}{$\begin{array}{c}\text { Beds/ } 100000 \text { population } \\
\text { at } 31 \text { December }\end{array}$}} & \multicolumn{4}{|c|}{$\begin{array}{l}\text { Estimated No of admissions anywhere } \\
\text { for residents of region }\end{array}$} & \multirow{3}{*}{$\begin{array}{c}\% \text { Average daily } \\
\text { bed occupancy in } \\
\text { non-termination of } \\
\text { pregnancy hospital } \\
1986\end{array}$} \\
\hline & & & \multirow[b]{2}{*}{1981} & \multirow[b]{2}{*}{1986} & \multicolumn{2}{|c|}{ No/100000 } & \\
\hline & 1981 & 1986 & & & 1981 & 1986 & \\
\hline Northern & $2 \cdot 1$ & $4 \cdot 0$ & 4421 & 8792 & 142 & 285 & 41 \\
\hline Yorkshire & $7 \cdot 6$ & $12 \cdot 7$ & 18919 & 26158 & 527 & 726 & 55 \\
\hline Trent & $8 \cdot 3$ & $10 \cdot 9$ & 19771 & 27532 & 431 & 594 & 47 \\
\hline East Anglia & $9 \cdot 3$ & $16 \cdot 2$ & 6522 & 12861 & 345 & 646 & 70 \\
\hline North West Thames & $54 \cdot 8$ & $35 \cdot 3$ & 34990 & 53165 & 1007 & 1524 & 45 \\
\hline North East Thames & $9 \cdot 1$ & $45 \cdot 8$ & 20344 & 42187 & 541 & 1122 & 59 \\
\hline South East Thames & $20 \cdot 3$ & $28 \cdot 4$ & 22384 & 43691 & 622 & 1207 & 51 \\
\hline South West Thames & $24 \cdot 0$ & $29 \cdot 9$ & 28665 & 46671 & 971 & 1574 & 51 \\
\hline Thames regions & $26 \cdot 2$ & $35 \cdot 2$ & 106383 & 185741 & 772 & 1343 & 52 \\
\hline Wessex & $8 \cdot 5$ & $20 \cdot 3$ & 15073 & 33391 & 548 & 1161 & 53 \\
\hline Oxford & $14 \cdot 9$ & $19 \cdot 4$ & 16960 & $28+19$ & 728 & 1148 & 52 \\
\hline South Western & $9 \cdot 8$ & $10 \cdot 8$ & 17119 & 24589 & 558 & 774 & 58 \\
\hline West Midlands & $6 \cdot 6$ & $12 \cdot 0$ & 29367 & 48356 & 567 & 933 & 68 \\
\hline Mersey & $11 \cdot 8$ & $13 \cdot 3$ & 13662 & 18447 & 557 & 764 & 67 \\
\hline North Western & $9 \cdot 1$ & $14 \cdot 1$ & 13540 & 33213 & 335 & 832 & 70 \\
\hline Wales & $6 \cdot 7$ & $9 \cdot 7$ & 11742 & 14195 & 418 & 503 & 40 \\
\hline England not otherwise specified & & & 2270 & - & & & \\
\hline All regions, England and Wales & $13 \cdot 3$ & $18 \cdot 9$ & 275752 & 461666 & 556 & 922 & \\
\hline
\end{tabular}

TABLE $\mathrm{V}-$ Financial provision for treatment episodes in independent hospitals for residents of England and Wales, excluding abortions and vasectomies, by age and sex

\begin{tabular}{|c|c|c|c|c|c|}
\hline \multirow[b]{2}{*}{$\begin{array}{l}\text { Age } \\
\text { (years) }\end{array}$} & \multirow[b]{2}{*}{ Sex } & \multicolumn{2}{|c|}{1981} & \multicolumn{2}{|c|}{1986} \\
\hline & & $\begin{array}{l}\text { Estimated No with } \\
\text { known financial } \\
\text { provision }\end{array}$ & $\begin{array}{l}\text { Proportion ( } \%) \\
\text { self financed }\end{array}$ & $\begin{array}{l}\text { Estimated No with } \\
\text { known financial } \\
\text { provision }\end{array}$ & $\begin{array}{l}\text { Proportion ( } \% \text { ) } \\
\text { self financed }\end{array}$ \\
\hline \multirow{2}{*}{$0-14$} & Male & 8538 & $26 \cdot 1$ & 16534 & $12 \cdot 4$ \\
\hline & Female & 6094 & $24 \cdot 1$ & 11847 & $13 \cdot 1$ \\
\hline \multirow[b]{2}{*}{$15-44$} & Male & 24318 & $23 \cdot 7$ & 50192 & $16 \cdot 2$ \\
\hline & Female & 46556 & $30 \cdot 1$ & 96995 & $24 \cdot 2$ \\
\hline \multirow{2}{*}{$45-64$} & Male & 23735 & $20 \cdot 0$ & 52023 & 14.9 \\
\hline & Female & 31921 & 23.9 & 63066 & $18 \cdot 4$ \\
\hline \multirow{2}{*}{$65-74$} & Male & 8057 & $35 \cdot 0$ & 18592 & $24 \cdot 6$ \\
\hline & Female & 7705 & $43 \cdot 5$ & 17907 & $32 \cdot 8$ \\
\hline \multirow{2}{*}{$\geqslant 75$} & Male & 3541 & $38 \cdot 2$ & 10000 & $33 \cdot 3$ \\
\hline & Female & 6102 & $58 \cdot 2$ & 14150 & $49 \cdot 1$ \\
\hline \multirow[t]{2}{*}{ All } & Male & 68189 & $24 \cdot 9$ & 147341 & $17 \cdot 6$ \\
\hline & Female & 98377 & $30 \cdot 8$ & 203965 & $24 \cdot 3$ \\
\hline
\end{tabular}

hospitals owned by American groups (56\%), by British groups $(56 \%)$, and independently $(59 \%)$ were closely similar to one another. There were also considerable regional variations, partly reflecting the varying ownership structures. Excluding the 14 hospitals specialising in abortions, there was a $70 \%$ occupancy in the North Western region and only $40 \%$ in Wales (see table IV). In the four Thames regions together the average daily occupancy was only $52 \%$.

\section{FINANCIAL PROVISION}

Information was provided about the way in which the episode was financed for $92 \%$ of cases in the sample. Excluding those for non-residents of England and Wales and abortions and vasectomy cases, $79 \%$ of all episodes were covered by insurance $(72 \%$ in 1981$)$ and only $21 \%(28 \%)$ were self financed (table V). In 
1986 insurance covered $82 \%$ of the non-vasectomy admissions of male residents of England and Wales and $76 \%$ of the non-termination of pregnancy admissions of females.

Between 1981 and 1986 the proportions of both men and women treated in independent hospitals who were not covered by insurance decreased substantially. The decrease was most noticeable in children under 15 for whom $25 \%$ of episodes were self financed in 1981 but only $13 \%$ in 1986 . The change in the proportion of treatments self financed between 1981 and 1986 among pensioners over 65 (a decrease from $44 \%$ to $34 \%$ ) was the same as for people of working age (a decrease from $25 \%$ to $19 \%$ ).

\section{Discussion}

Despite the growth of the for profit hospitals since 1981 there has been little overall change in the profile of the clinical activity undertaken in the short stay independent hospital sector. For example, although it is estimated that for residents of England and Wales nearly three times as many coronary artery bypass grafts were carried out in independent hospitals in 1986 as in 1981 , there were still fewer than 1000 such operations performed (though there were a further 1600 such operations performed on overseas residents). There is little evidence to support the contention that the independent sector had expanded into "high technology" surgical activity between 1981 and 1986 . Even excluding abortions, the activity still consists largely of routine cold elective surgery. There seems little scope therefore for the NHS to unload much of the costly high tech surgery it undertakes on to the independent sector.

One notable change that has taken place since 1981 is the increase in the number of resident medical practitioners in independent hospitals. In 1982 (the first year for which statistics were collected) only 66 out of all acute and non-acute independent hospitals had a resident medical practitioner, but by 1986 this had increased to 123 hospitals." "Thus at least in this respect the independent sector in 1986 was more capable of caring for patients who were undergoing complicated surgery than it was in 1981. But since there is little evidence of a more complex activity profile the conclusion must be either that resident doctors were necessary in 1981, though largely absent, or that they are unnecessary now.

There is also little evidence to suggest that the considerable regional imbalance in the level of provision and activity of independent hospitals noted in 1981 has diminished. In 1986, $51 \%$ of the bed days available in general independent hospitals were located in the Thames regions, and $40 \%$ of all non-abortion admissions were for residents of these regions. The shortfall between the supply of beds and number of admissions in the Thames regions is partly made up by overseas residents and partly represents a relatively larger number of beds. Nationally an average daily occupancy of only $55 \%$ means that at least in the short term there is some spare capacity in independent hospitals which the NHS could "buy." We have not measured the extent to which this is already happening, but it is reported that only 10655 medical and surgical NHS patients were treated in non-NHS facilities in England in $1986^{12}$ and $4175(39 \%)$ of these patients were resident in one small regional health authority East Anglia. Nor do we know whether the estimated average daily occupancy of hospitals in the for profit sector $(57 \%)$ is commercially viable, but it has been suggested that the break even level is $70 \%,{ }^{13}$ in which case the term "for profit" may be misleading.
Despite the great expansion of private health insurance cover since 1981 the known demographic characteristics of users of the independent hospitals remained the same, with three quarters of all people admitted to the independent hospitals in both 1981 and 1986 being of working age. Furthermore, although the expansion in private health insurance in the past five years has greatly increased the proportion of private treatment episodes that are covered by insurance, there is no evidence that it was any easier for retired people compared with other age groups to obtain and pay for such insurance in 1986 than in 1981. The implications are that the expansion of private health insurance has merely been "more of the same" and that there has been no change in the breadth of coverage.

In the current reviews of the NHS being undertaken there should perhaps be borne in mind three clear facts about the independent hospital sector presented here. Firstly, at the present time the independent hospitals are only carrying out on any appreciable scale a programme of routine cold elective surgery. They may not be geared up to perform more complex high tech procedures to any extent that would provide relief to the NHS. Secondly, the facilities available and the use of independent hospitals is still very unevenly distributed across England and Wales. Any proposal to use the independent acute sector to relieve the NHS could not be expected to work across the whole of the country, at least in the short term. Thirdly, the evidence is that despite the recent expansion of independent hospitals it is still predominantly people of working age who are paying for private treatment in them. There is currently no evidence then that an expanded independent sector could provide health care to all groups of people, and this is likely to continue to be the case until new health insurance policies are available to new groups of people.

We thank the owners, directors, and staff of the independent hospitals for their collaboration; the officers of the Independent Hospitals Association; $\mathrm{Mr}$ John Randle; $\mathrm{Mr}$ Oliver Rowell of the Nuffield Nursing Homes Trust; $\mathrm{Mr}$ Barry Caulfield of British United Provident Association; and Mr David Cavers of Private Patients Plan for their help.

The work was funded by the Department of Health and Social Security, which, with Trent Regional Health Authority, maintains the Medical Care Research Unit. We are grateful for their support. The views expressed in this paper, however, are those of the authors alone.

I Williams BT, Nicholl JP, Thomas KJ, Knowelden J. Analysis of the work of independent acute hospitals in England and Wales, 1981. Br Med 7 1984:289:446-8.

2 Independent Hospitals Association. Survey of acute hospitals in the independent sector. London: IHA, 1986.

3 Higgins J. The business of medicine. Private health care in Britain. London Macmillan, 1988.

+ Anonymous. Supplementary annual report of council. Appendix VI: evidence to the government internal review of the National Health Service. Br. Med 7 $1988 ; 296: 1411-8$

5 Nicholl JP, Beeby NR, Williams BT. The role of the private sector in elective surgery in England and Wales 1986. Br.Med $\mathcal{F}$ 1989;298:243-7.

6 Department of Health and Social Security. Private hospitals, homes and climic registered under section 23 of the registered homes act. 31st December 1986. National regional and district summaries. London: Government Statistical Service, 1987.

Directory of independent hospitals and health services 1986/87. Harlow: Longman. 1986.

8 Office of Population Censuses and Survers. Classification of surgical operutions. 3rd revision. London: OPCS, 1975.

9 Office of Population Censuses and Surveys. Abortion statistics 1986 Fingland and Wales. London: HMSO, 1987. (Series AB No 13.)

10 Department of Health and Social Security. Hospital statistics for 1983. Nutional Summary, 1987. London: DHSS, 1987. (SH3 EDP4.)

11 Department of Health and Social Security. Private hospitals, homes and clinic registered under section 23 of the registered homes act. 31 st December 1982.
repartment National regional and district summaries. London: Government Statistical Service, 1983.

12 Department of Health and Social Security. Patients receiving treatment under contractual arrangements with institutions outside the NHS in England - 1986. London: DHSS, 1988. (Form SH9.

13 Grant C. Privale health care in the UK: a review. London: Economis Intelligence Unit, 1985:32. (Special report No 207.) 